\title{
FARKLI KAYNAKLARDAN İZOLE EDİLMİŞ LAKTİK ASİT BAKTERİLERİNİN EKZOPOLİSAKKARİT ÜRETIMII VE KOLESTEROL ASİMİLASYON YETENEKLERININ BELİRLENMESİ
}

\author{
Duygu Alp, ${ }^{*}$ Hakan Kuleaşan \\ ${ }^{1}$ Süleyman Demirel Üniversitesi, Mühendislik Fakültesi, Gıda Mühendisliği Bölümü, Isparta, Türkiye
}

Geliş / Received: 04.06.2018; Kabul / Accepted: 09.02.2019; Online bask1 / Published online: 26.02.2019

Alp, D., Kuleaşan, H. (2019). Farklı kaynaklardan izole edilmiş laktik asit bakterilerinin ekzopolisakkarit üretimi ve kolesterol asimilasyon yeteneklerinin belirlenmesi. GIDA (2019) 44 (2): 191-201 doi: 10.15237 /gida.GD18059

Alp, D., Kuleasan, H. (2019). Determination of excopolisaccharide production and cholesterol assimilation abilities of lactic acid bacteria isolated from different sources. GID A (2019) 44 (2): 191-201 doi: 10.15237/gida.GD18059

\section{ÖZ}

Bağırsak sistemimizde yer alan yararlı mikroorganizmaların önemli özelliklerinden birisi gastrointestinal sistemdeki farklı koşullara karşı direnç gösterebilmeleridir. Bu koşullar arasında safra tuzlarına karşı direnç ve düşük pH'da gelişim yer almaktadır. Gastrointestinal sistemde canlllklarını sürdürebilmek için yararlı bakteriler spesifik enzim sentezi veya ekzopolisakkarit üretimi gibi çeşitli savunma mekanizmaları geliştirmişlerdir. Bu çalışmada çeşitli fermente gidalardan ve bitkilerden izole edilmiş laktik asit bakterilerinin safra tuzu dirençleri, düşük pH'da gelişim özelliklerinin yanı sıra, ekzopolisakkarit üretimleri ve kolesterol asimilasyon yetenekleri belirlenmiștir. Ekzopolisakkarit (EPS) üretimlerinin 11.9 ile $1.1 \mathrm{mg} / \mathrm{L}$ arasında değiştiği belirlenirken toplam kolesterol asimilasyon yüzdeleri \% 60.71 ile \% 16.71 arasında değişim göstermiştir. Kolesterol asimilasyon yetenekleri ile EPS üretimleri arasında bir bağlant bulunamamıştr.

Anahtar kelimeler: Kolesterol asimilasyonu, ekzopolisakkarit, düşük pH, safra tuzu direnci

\section{DETERMINATION OF EXCOPOLISACCHARIDE PRODUCTION AND CHOLESTEROL ASSIMILATION ABILITIES OF LACTIC ACID BACTERIA ISOLATED FROM DIFFERENT SOURCES}

\begin{abstract}
One of the most important features of the intestinal flora is resistance to many conditions in the gastrointestinal tract. These include resistance to bile salt and growth at low $\mathrm{pH}$. Bacteria have developed various defense mechanisms, such as specific enzymes, exopolysaccharide production, against Gastrointestinal system, In our study, strains of lactic acid bacteria isolated from various fermented foods and plants and all the strains were determined of their bile salt and low $\mathrm{pH}$ resistance. The strains were also tested for their exopolysaccharide production and total cholesterol assimilation properties. EPS production was observed at rations between 11.9 to $1.1 \mathrm{mg} / \mathrm{L}$, and total cholesterol assimilation percentages ranged from 60.71 to 16.71 . There was no relevance between cholesterol assimilation ability and their EPS production.
\end{abstract}

Keywords: Cholesterol assimilation, exopolysaccharide, low $\mathrm{pH}$, bile salt resistance.

\footnotetext{
* Yazışmalardan sorumlu yazar / Correspondig author

$\triangle$ duygualp1@gmail.com (c) (+90) 5435876811

具 $(+90) 2462111542$
} 


\section{GİRİ̧̧}

Kan dolaşımındaki yüksek kolesterol miktarı insanlarda kalp-damar sistemi hastalıkları için risk faktörü oluşturmaktadır. Kalp-damar sistemi hastalıkları, kanda aşırı kolesterol bulunması ile yakın ilişkili olan ve gelişmiş ülkelerdeki ölüm sebepleri içerisinde en yüksek orana sahip olanlardan birisidir (Ahn vd., 2003; Xie vd., 2011; Ahire vd., 2012; Castorena-Alba vd., 2017). Dünya sağllk örgütü (WHO), 2030 yllına kadar kardiyovasküler hastalıkların dünyada yaklaşı 23.6 milyon insanı etkileyen önemli bir ölüm nedeni olacağını öngörmektedir (Ahire vd., 2012; Alp ve Ertürkmen, 2017). Yüksek seviyede toplam kolesterol ve özellikle kabul edilir sinırların üzerinde olan düşük yoğunluklu lipoprotein (LDL) kolesterol, hiperkolesterolemiye neden olmaktadır (Burhan vd., 2017). Vücudumuzda kolesterol sentez hizı ile kolesterol atılım hizı farklı olabilmektedir. Bu nedenle dengenin sağlanabilmesi için bazı düzenleyici mekanizmalar mevcuttur. Kolesterol vücudumuzdan iki şekilde atılmaktadır. İlk yol feçesle atılan safra asitlerine dönüştürülmesi şeklinde olup, ikinci yol ise safra içine salgilanarak atılabilmesi için bağırsaklara ulaştırılması şeklindedir (Ulukaya, 1997). Bu iki yoldan ikincisi olan yani, safra içerisine salgilanması şeklinde gerçekleşen yol kolesterolün, vücuttan atılması için izlenen en önemli yoldur. Serbest kolesterol, sulu çözeltilerde neredeyse hiç çözünmez, fakat safrada, safra asitleri ve lesitin gibi lipitler vasıtasıyla çözünebilir hale gelir (Tok, 2007). Safra asitleri çok basamaklı bir metabolik yol izleyerek karaciğer tarafindan sentezlenirler. Oluşan bileşikler "primer" safra asitleri olarak adlandırilan kolik asit ve kenodeoksikolik asittir. Enterococcus, Bifidobacterium, Fusobacterium, Clostridium, Bacteroides ve Lactobacillus gibi bağırsak bakterileri glisin ve taurin aminoasitlerini safra tuzlarından, safra tuzu hidrolaz (BSH) enzimini kullanarak ayırabilmektedirler. Bu olaya "dekonjugasyon" ad1 verilir (Ulukaya, 1997). Safra asitlerinin deterjan etkisi, konjuge safra tuzlarına kıyasla daha azdır. $\mathrm{Bu}$ nedenle dekonjuge olmuş (serbest) safra asitleri, kolesterolün emiliminde, konjuge safra tuzları kadar etkili değildirler. Bu sebepten dolay1 safra tuzu dekonjugasyonunun, kolesterolün çözünürlügünü azalttığı, dolayısıyla bağırsaklardan emilimini ve ayrıca enterohepatik döngüyle karaciğere dönen safra asidi miktarını azalttığ1 bundan dolayı da, karaciğerdeki safra asidi üretimini arttırdığı düşünülmektedir (Hofmann vd., 1983; Gilliand vd., 1985; Ulukaya 1997; Ahn vd., 2003; Tok, 2007; Tok ve Aslım 2010; Anila vd., 2016). Laktik Asit Bakterilerinin (LAB) probiyotik özellik gösterebilmesi için ağı yoluyla alındığında mide asitliği ve safraya karşı tolerans, safra tuzu hidrolaz aktivitesi, bağışıklık sistemi modülasyonu, patojenler ile rekabet gibi özelliklere sahip olması gerekmektedir (Ünal ve Erginkaya, 2010; Öztürk ve Tiryaki Gündüz, 2018). Ayrıca bazı probiyotik suşların kandaki yüksek kolesterol seviyesini düşürebilme yeteneklerinden dolayı son yıllarda bu amaçla kullanımları gündeme gelmiştir (Pinto vd., 2006; Tok, 2007; Moal ve Servin, 2014; Iranmanesh vd., 2014; Özden Tuncer ve Tuncer, 2014; Arief vd., 2015; Chang-Qing ve Rong 2015; Syah vd., 2017; Burhan vd., 2017). Çalışmalar, plazma kolesterolü ve düşük yoğunluklu lipoprotein kolesterolü düşürmek için bazı kültürleri içeren süt ürünlerinin tüketiminin faydalı olabileceğini göstermiştir. İnsan, fare, domuz ve siçanlarda yapılan çalışmalar sonucu LAB'nin serum kolesterolünü azaltmada önemli bir etki gösterebileceği görülmüştür. Özellikle Lactobacillus cinsine ait baz1 türlerin potansiyel hipokolesterolemik aktiviteye sahip olduğu gözlemlenmiştir. Bu nedenle probiyotik içeren süt ürünlerinin tüketimi, serum kolesterolü düşürmek için tavsiye edilmektedir (Wang vd., 2014). Probiyotiklerin hangi mekanizma ile serum kolesterol düzeylerini düşürdüğü henüz tam olarak aydınlatılamamıştır. Düşünülen olası mekanizmalar arasında kolesterolün bakteri hücresi tarafindan asimilasyonu, bakteriyel asit hidrolazlar ile safra asitlerinin dekonjugasyonu, kolesterolün bakteri duvarına bağlanması, hepatik kolesterol sentezinin inhibisyonu veya kolesterolün plazmadan karaciğere doğru yön değiştirmesi vardır (Noh vd., 1997; KoppHoolihan vd., 2001; Kaur vd., 2002; Gill ve Guarner, 2004; Coşkun, 2006; Belviso vd., 2009;).

\section{MATERYAL VE YÖNTEM}

Çalışmada çeşitli fermente gıdalardan ve bitkilerden izole edilerek 16S rRNA dizi analizi ile 
tür düzeyinde tanımlamaları yapılmış (GEN Plaza Biyoteknoloji Merkezi, Ankara) 15 adet laktik asit bakterisi kullanılmıstır (Alp, 2018).

\section{İzolatların Safra Tuzu, Düşük pH Dayanimları}

Denemeler MRS (DeMan-Rogosa-Sharpe, Merck, Almanya) siv1 besiyerinde $30^{\circ} \mathrm{C}^{\prime} \mathrm{de} 18$ saat geliştirilen bakteri kültürleri kullanılarak yapılmıştır. Gelişmenin ardından kültürler safra tuzuna karşı direnç özelliğinin belirlenmesi amacıyla \% 1 oranında safra tuzu içeren Fosfat Tamponu Çözeltisi (PBS) içerisine \% 1 oranında ilave edilmiştir. $37^{\circ} \mathrm{C}$ 'de yapılan inkübasyonun başlangıç, 4. ve 24. saatlerinde örneklerden alınan numunelerin sayımları seri dilüsyonlar sonrası damla kültür yöntemi ile MRS katı besiyerlerine 3 paralel olacak şekilde yapılmıştır. $37^{\circ} \mathrm{C}^{\prime}$ de 48 saat yapilan inkübasyonun ardindan kontrol ve deneme gruplarındaki koloniler sayılarak değerler eşitlik (1)'e göre hesaplanmıştır (Eryllmaz, 2011; Horáčková vd., 2011; Sahadeva vd., 2011; Jamaly vd., 2011; Xiao vd., 2014; Tokatlı vd., 2015; Soliman vd., 2015).

$$
\text { Canlılık }(\%)=\frac{\text { Canlı kalan hücre sayısı }(\mathrm{kob} / \mathrm{mL})}{\text { Başlangıçta inoküle edilen hücre sayısı }(\mathrm{kob} / \mathrm{mL})} \times 100
$$

Kültürlerin düşük pH koşullarına dayanımlarının belirlenmesi amaciyla kullanılan $\mathrm{pH}$ derecesi ve inkübasyon süresi, besinler insan sindirim sisteminden geçerken midede kalma süresi baz alınarak belirlenmiştir. Besinlerin genel olarak midede kalma süresi 3 saat olup bu süre içerisinde midenin pH's1 1 ile 4 arasında değişmektedir (Vinderola vd., 2000). Bu amaçla kültürler, MRS sıvı besiyerinde $30^{\circ} \mathrm{C}$ 'de 18 saat inkübe edilmiştir. Daha sonra PBS tamponun pH's1 3.0 olacak şekilde ayarlanmıştır. pH'sı ayarlanan PBS tampona aktif kültürlerden $\% \quad 1$ oraninda aşlanarak, $37^{\circ} \mathrm{C}$ 'de 3 saat inkübe edilmiştir. İnkübasyonun başlangıç, 1 . ve 3. saatlerinde örneklerden alınan numunelerin sayımları seri dilüsyon sonrası damla kültür yöntemi ile MRS katı besiyerlerine 3 paralel olacak şekilde yapılmıştır. $37^{\circ} \mathrm{C}$ 'de 48 saat yapılan inkübasyonun ardindan kontrol ve deneme gruplarındaki koloniler sayılarak değerler eşitlik (1)'e göre hesaplanmıştır (Eryılmaz, 2011; Horáčková vd., 2011; Sahadeva vd., 2011; Jamaly vd., 2011; Soliman vd., 2015).

\section{İzolatların Ekzopolisakkarit Üretimleri}

İzolatların farklı karbonhidrat kaynaklarını kullanarak ekzopolisakkarit üretimlerinin belirlenmesi amaciyla MRS besiyeri modifiye edilerek kullanılmıştır. $\mathrm{Bu}$ amaçla hem standart MRS besiyeri, hem de bileşiminde yer alan glukoz yerine fruktoz, laktoz ve sükroz $\% 2$ olacak şekilde kullanılmıştır. Çalışma öncesinde EPS üreticisi olabilecek suşların belirlenmesi için kültürler önce farklı şekerler içeren MRS katı besiyerinde $30^{\circ} \mathrm{C}$ 'de 3 gün inkübe edilmişlerdir. İnkübasyonun sonunda mukoz yapida koloni oluşturan izolatlar muhtemel ekzopolisakkarit üreticisi olarak seçilmişlerdir. Seçilen koloniler aynı şeker bileşiminde hazırlanmış MRS sıvı besiyerine alınarak tekrar $30^{\circ} \mathrm{C}$ 'de 3 gün inkübe edilmişlerdir. İnkübasyonun sonunda örnekler 10 dakika $100^{\circ} \mathrm{C}$ 'de kaynatılmış, ardından $900 \mu \mathrm{L} \% 85^{\prime}$ lik TCA ve $900 \mu \mathrm{L}$ örnek olacak şekilde darası alınmış $2 \mathrm{~mL}$ 'lik santrifüj tüplerine alınarak $10.000 \mathrm{rpm}$ 'de 25 dakika santrifüjlenmiştir. Santrifüj sonrası üstte kalan süpernatanttan $500 \mu \mathrm{L}$ alınmış üzerine 1500 $\mu \mathrm{L}$ soğuk etanol eklenerek 1 gece $-18^{\circ} \mathrm{C}$ 'de bekletilmiştir. Daha sonra tekrar 10.000 rpm'de 25 dakika santrifüjlenmişlerdir. Santrifüj sonrası süpernatant dökülmüş etanolün uzaklaştırılması için $60^{\circ} \mathrm{C}$ 'de 1 gece bekletilmiştir. Kurutulan tüpler sürenin sonunda tekrar tartılmış ve sonuçlar $\mathrm{mg} / \mathrm{L}$ olacak şekilde hesaplanmıştır (Smitinont, vd., 1999; Feng vd., 2012). Elde edilen sonuçların istatistiksel değerlendirmesinde Minitab versiyon 16 programı kullanılmışıı

\section{İzolatların Kolesterol Asimilasyonu}

İzolatların kolesterol asimilasyon özelliklerinin belirlenmesi amaciyla Anandharaj ve Sivasankari (2014) çalışmalarında kullandığı yöntem modifiye edilmiştir. MRS besiyeri \% 0.3 safra tuzu (Merck) ve $110.70 \mathrm{mg} / \mathrm{dL}$ kolesterol (Sigma Aldrich) içerecek şekilde hazırlanmıştır. Aktif kültürlerden $\% 1$ oranında aşılama yapıldıktan sonra anaerob ortamda $37^{\circ} \mathrm{C}$ 'de 18 saat inkübe edilmiştir. 
İnkübasyonun sonunda izolatların MRS besiyerinde kalan toplam kolesterol miktar1 Süleyman Demirel Üniversitesi Tip Fakültesinde Beckman Coulter AU5800 model analizör ile belirlenmiştir.

\section{BULGULAR VE TARTIŞMA}

Safra Tuzuna Karşı Gelişim

Çalıșmamızda 15 adet laktik asit bakterisinin \% 1 safra tuzuna karşı $0 ., 4$ ve 24 saat sonundaki gelişimleri belirlenmiştir. \% 1 safra tuzuna karş1 24 saat sonunda izolatların hepsi canlilikların korumuştur. Canll11k yüzdeleri \% 104.23 ile \% 88.73 arasındadır. Çizelge 1'de safra tuzuna karşı 0. 4. ve 24 . saat sonundaki gelişen mikroorganizmaların logaritmik sonuçları, canlılık oranları ve izolasyon kaynakları verilmiştir.

Çizelge 1. İzolatların safra tuzunda 0., 4. ve 24. saat inkübasyon sonundaki canlılık oranları Table 1. Viability of isolates at the end of 0,4 and 24 hours of incubation in bile salt solution

\begin{tabular}{|c|c|c|c|c|c|c|}
\hline $\begin{array}{l}\text { Mikroorganizma } \\
\text { izolasyon kaynağ1 } \\
\text { Isolation source of } \\
\text { microorganism }\end{array}$ & $\begin{array}{l}\text { Mikroorganizma } \\
\text { Microorganism }\end{array}$ & $0 . \mathrm{h}$ & 4. h & 24. $\mathrm{h}$ & $\begin{array}{c}\text { 0-4. h Canlilik } \\
\text { Oranı (\%) } \\
\text { 0-4. b Viability } \\
\text { Ratio (\%) }\end{array}$ & $\begin{array}{c}\text { 0-24. h Canlilik } \\
\text { Oran1 (\%) } \\
\text { 0-24. b Viability } \\
\text { Ratio (\%) }\end{array}$ \\
\hline $\begin{array}{l}\text { Tulum Peyniri } \\
\text { Tulum Cheese }\end{array}$ & L. case $i \mathrm{DA} 4$ & $7.50 \pm 0.37$ & $7.33 \pm 0.59$ & $7.22 \pm 0.40$ & $97.73 \pm 3.96$ & $96.26 \pm 2.53$ \\
\hline $\begin{array}{l}\text { Bergama Tulumu } \\
\text { Bergama Tulum } \\
\text { Cheese }\end{array}$ & W. cibaria DA8 & $7.98 \pm 0.40$ & $7.61 \pm 0.70$ & $7.88 \pm 0.44$ & $95.36 \pm 5.02$ & $98.74 \pm 2.75$ \\
\hline $\begin{array}{l}\text { Tulum Peyniri } \\
\text { Tulum Cheese }\end{array}$ & $W$. cibaria DA28 & $7.34 \pm 0.06$ & $7.34 \pm 0.13$ & $7.26 \pm 0.13$ & $100.00 \pm 1.36$ & $98.91 \pm 1.36$ \\
\hline $\begin{array}{l}\text { Turşu } \\
\text { Pickle }\end{array}$ & L. plantarum DA100 & $7.05 \pm 0.04$ & $6.93 \pm 0.24$ & $6.81 \pm 0.00$ & $98.29 \pm 1.77$ & $96.59 \pm 1.00$ \\
\hline $\begin{array}{l}\text { Beyaz Peynir } \\
\text { White-Brined Cheese }\end{array}$ & L. fermentum DA134 & $8.49 \pm 0.12$ & $8.40 \pm 0.52$ & $8.40 \pm 0.50$ & $98.93 \pm 3.38$ & $98.93 \pm 3.38$ \\
\hline $\begin{array}{l}\text { Ezine Peyniri } \\
\text { Ezine Cheese }\end{array}$ & L. plantarum DA135 & $7.79 \pm 0.50$ & $7.33 \pm 0.90$ & $8.12 \pm 0.47$ & $94.09 \pm 8.04$ & $104.23 \pm 2.95$ \\
\hline $\begin{array}{l}\text { Tulum Peyniri } \\
\text { Tulum Cheese } \\
\text { Fermente Sucuk }\end{array}$ & L. plantarum DA140 & $7.18 \pm 0.09$ & $7.18 \pm 0.16$ & $7.12 \pm 0.11$ & $100.00 \pm 1.45$ & $99.16 \pm 1.30$ \\
\hline $\begin{array}{l}\text { Turkish Dry } \\
\text { Fermented Sausage } \\
\text { Fermente Sucuk }\end{array}$ & L. plantarum DA199 & $8.25 \pm 0.52$ & $7.82 \pm 0.43$ & $7.88 \pm 0.43$ & $94.78 \pm 2.75$ & $95.51 \pm 2.70$ \\
\hline $\begin{array}{l}\text { Turkish Dry } \\
\text { Fermented Sausage } \\
\text { Fermente Sucuk }\end{array}$ & L. plantarum Da218 & $7.69 \pm 0.61$ & $7.81 \pm 0.18$ & $7.51 \pm 0.48$ & $101.56 \pm 1.54$ & $97.65 \pm 3.08$ \\
\hline $\begin{array}{l}\text { Turkish Dry } \\
\text { Fermented Sausage }\end{array}$ & L. plantarum DA225 & $7.85 \pm 0.52$ & $7.70 \pm 0.28$ & $7.90 \pm 0.63$ & $98.08 \pm 1.93$ & $100.63 \pm 4.27$ \\
\hline $\begin{array}{l}\text { Zeytin } \\
\text { Olive }\end{array}$ & L. plantarum DA245 & $8.11 \pm 0.39$ & $7.89 \pm 0.18$ & $7.61 \pm 0.20$ & $97.28 \pm 5.38$ & $93.83 \pm 1.61$ \\
\hline $\begin{array}{l}\text { Kara Dut } \\
\text { Black Mulberry }\end{array}$ & L. plantarum DA255 & $7.90 \pm 0.53$ & $7.61 \pm 0.39$ & $7.62 \pm 0.51$ & $96.32 \pm 2.50$ & $96.45 \pm 3.29$ \\
\hline $\begin{array}{l}\text { Biberiye } \\
\text { Rosemary }\end{array}$ & L. coryniformis DA256 & $7.41 \pm 0.86$ & $7.52 \pm 0.30$ & $7.52 \pm 0.30$ & $101.48 \pm 2.03$ & $101.48 \pm 2.02$ \\
\hline $\begin{array}{l}\text { Turunç } \\
\text { Bitter Orange }\end{array}$ & L. coryniformis DA263 & $7.36 \pm 0.09$ & $7.18 \pm 0.02$ & $7.22 \pm 0.03$ & $97.55 \pm 1.05$ & $98.09 \pm 1.08$ \\
\hline $\begin{array}{l}\text { Yeni dünya } \\
\text { Japanese Medlar }\end{array}$ & L. lactis DA268 & $8.17 \pm 0.14$ & $7.52 \pm 0.23$ & $7.25 \pm 0.36$ & $92.04 \pm 1.71$ & $88.73 \pm 2.29$ \\
\hline
\end{tabular}

Eryılmaz, (2011) çalışmasında vajinal sekresyondan izole etmiş olduğu laktik asit bakterilerinin $\% 0.3 \% 0.5$ ve $\% 1$ oranında safra tuzuna karşı dirençliliğini tespit etmiştir. L. brevis OZV suşunun 4. saatte $\%$ 0.3'lük konsantrasyonda canlilik oranını \%95.98 olarak tespit etmiştir. Suş, $\% \quad 0.5$ ve $\%$ 1'lik konsantrasyonlarda da yine bu rakamlara ulaşmıştır. Jamally vd. (2011) çalışmalarında Fas’a özgü süt ürünlerinden izole ettikleri L. plantarum , L. paracasei ve L. brevis suşlarının $\% 0.2, \% 0.3, \%$ 0.5 ve $\% 1$ oranında safra tuzuna karş1 0 ., ve 24 ., saatlerdeki dirençliliklerini tespit etmiştir. İzolatlar $\% \quad 0.2$ ve $\% \quad 0.3$ safra tuzunda iyi gelişim gösterirken $\% \quad 1$ safra tuzuna karşı canlilik değerleri düşük çıkmıştır. İzolatların \% 1 safra 
tuzuna karşı en yüksek canlılık oranı \% 65.20 olarak belirlenmiştir. Sharma vd. (2016) geleneksel süt ürünlerinden elde ettiği laktik asit bakterilerinin $\% 0.3,0.7,1.0,1.5$ ve $\% 2$ safra tuzuna karşı 24. saat sonundaki dirençliliklerini tespit etmiştir. L. casei suşlarının bu oranların tamamında yaklaşık \% 90-95 aralığında canlilık gösterdiğini tespit etmişlerdir. Wang vd. (2014) hardaldan izole ettikleri 50 adet laktik asit bakterisinin $\% 0.5$ ve $\% 1$ safra tuzuna dirençlilik özelliklerini incelemişlerdir. Mikroorganizmalardan sadece Lactobacillus suşlar1 safra tuzuna dirençlilik gösterebilmiştir. Anandharaj ve Sivasankari (2014) yaptıkları çalışmada Lactobacillus ve Weissella suşlarının $\% 0.3$ ve $\% 0.5$ oranında safra tuzuna karşı dirençliliğini tespit etmişlerdir. \% 0.3 'lük safra tuzunda Lactobacillus suşları ortalama \% 81 Weissella suşları ise $\% 84$ oranında canlilık göstermişlerdir. \% $0.5^{\prime}$ lik safra tuzunda ise bu oranlar \% 30'lara kadar inmiștir. Uraipan ve Hongpattarakere (2015) çalışmalarında laktik asit bakterileri ve bifidobakterlerin gida kaynaklı patojen mikroorganizmalara karşı antogonistik etkilerini incelemişlerdir. $\mathrm{Bu}$ amaçla izolatların \% 0.3 safra tuzuna karşı direncini incelemişlerdir. Suşlardan en iyi canll1.̆̆1 B. longum NIF7AN2 \% 95.80, L. plantarum CIF17AN8 \% 80.03 olarak göstermiştir. Yapılan çalışmalarda ağırlıklı olarak \% 0.3 ve $\%$ 0.5 oranında safra tuzu ile çalışıldığı görülmüştür.
Çalışmamızda ise \% 1 oranında safra tuzu ile deneme yapılmıştır. Çalışmada mikroorganizmaların vücudumuzda gelişimlerini destekleyici herhangi bir ortam olmadan safra tuzlar1 ile karşılaştıkları düşünülerek zengin besin içeriği ve tamponlama özelliği olan MRS besiyeri yerine PBS'de yapılmış ve bu durum göz önüne alındığında elde edilen sonuçların iyi bir canlılık oran1 olduğu düşünülmüştür.

\section{Düşük pH'da Gelişim}

Mide pH'sı 1-4 arasında değişmektedir ve besinler midede en az 90 dakika kalmaktadır. Bu nedenle mikroorganizmaların uygulanan $\mathrm{pH}$ ve süreye dayanıp dayanamadıklarını belirleyebilmek amaciyla in vitro tolerans testleri uygulanmaktadır (Castorena-Alba vd., 2017). Çalışmamızda da bu amaçla 15 adet laktik asit bakterisinin $\mathrm{pH} 3.0$ 'de 0. . 1 . ve 3 . saatlerdeki canlllik oranlar1 belirlenmiştir. Asit direnci suşlar arasında farkl1lık göstermiş ve 8 adet izolat 3 . saatin sonunda canlılığını yitirmiştir. Suşlar arasında farklı illerden alınmıs tulum peynirinden izole edilen $W$. cibaria DA8 ve $W$. cibaria DA28 suşlar1 3. saatin sonunda oldukça iyi bir canll11k yüzdesi göstermişlerdir. 3 . saatin sonunda canlllı̆̆ını koruyan diğer bir grup ise fermente sucuk izolatlar1 olan $L$. plantarum DA199, L. plantarum DA218 ve L. plantarum DA225'dir. Çizelge 2'de Mikroorganizmaların $\mathrm{pH}$ 3.0'e karş1 0 ., 1. ve 3. saat sonundaki gelişme durumları ve canlilık oranları verilmiştir.

Çizelge 2. Mikroorganizmaların pH 3.0'e karşı canlılık sonuçlanı

Table 2. The viability results of microorganisms against $p H 3.0$

\begin{tabular}{|c|c|c|c|c|c|}
\hline $\begin{array}{l}\text { Mikroorganizma } \\
\text { Microorganism }\end{array}$ & $0 . \mathrm{h}$ & 1. $\mathrm{h}$ & 3. $\mathrm{h}$ & $\begin{array}{l}\text { 0-1. h Canll11k (\%) } \\
\text { 0-1. b Viability (\%) }\end{array}$ & $\begin{array}{l}\text { 0-3. h Canl1lik (\%) } \\
0-3 . \text { b Viability (\%) }\end{array}$ \\
\hline L. casei DA4 & $7.20 \pm 0.26$ & $6.91 \pm 0.37$ & $7.13 \pm 0.65$ & $95.97 \pm 2.33$ & $99.02 \pm 4.48$ \\
\hline$W$. cibaria $\mathrm{DA} 8$ & $7.03 \pm 0.49$ & $7.57 \pm 0.11$ & $7.50 \pm 0.82$ & $107.68 \pm 1.30$ & $106.68 \pm 6.61$ \\
\hline$W$. cibaria $\mathrm{DA} 28$ & $8.28 \pm 0.39$ & $7.91 \pm 0.50$ & $8.35 \pm 0.51$ & $95.53 \pm 3.17$ & $100.84 \pm 3.26$ \\
\hline L. plantarum DA100 & $8.42 \pm 0.33$ & $7.49 \pm 0.43$ & 0.00 & $88.95 \pm 2.69$ & 0.00 \\
\hline L. fermentum DA134 & $8.50 \pm 0.46$ & $5.73 \pm 0.20$ & $4.55 \pm 0.02$ & $67.41 \pm 1.57$ & $53.52 \pm 1.05$ \\
\hline L. plantarum DA135 & $8.13 \pm 0.31$ & $7.68 \pm 0.33$ & 0.00 & $94.46 \pm 2.12$ & 0.00 \\
\hline L. plantarum DA140 & $8.02 \pm 0.23$ & $5.06 \pm 0.10$ & 0.00 & $63.92 \pm 1.27$ & 0.00 \\
\hline L. plantarum DA199 & $8.32 \pm 0.50$ & $8.18 \pm 0.42$ & $8.04 \pm 0.40$ & $98.31 \pm 2.61$ & $96.63 \pm 2.54$ \\
\hline L. plantarum DA218 & $8.32 \pm 0.22$ & $7.90 \pm 0.27$ & $6.74 \pm 0.23$ & $94.95 \pm 1.84$ & $81.00 \pm 1.68$ \\
\hline L. plantarum DA225 & $8.69 \pm 0.34$ & $7.84 \pm 0.28$ & $6.54 \pm 0.21$ & $90.21 \pm 1.92$ & $75.25 \pm 1.63$ \\
\hline L. plantarum DA245 & $8.59 \pm 0.27$ & $7.96 \pm 0.14$ & 0.00 & $92.66 \pm 1.38$ & 0.00 \\
\hline L. plantarum DA255 & $7.63 \pm 0.47$ & $7.60 \pm 0.14$ & 0.00 & $72.08 \pm 1.38$ & 0.00 \\
\hline L. coryniformis DA256 & $8.19 \pm 0.02$ & $7.04 \pm 0.34$ & 0.00 & $85.95 \pm 2.18$ & 0.00 \\
\hline L. coryniformis DA263 & $7.83 \pm 0.16$ & $7.60 \pm 0.00$ & 0.00 & $97.06 \pm 1.00$ & 0.00 \\
\hline L. lactis DA268 & $8.12 \pm 0.18$ & 0.00 & 0.00 & 0.00 & 0.00 \\
\hline
\end{tabular}


Horáčková vd. (2011) çalışmalarında farklı Lactobacillus şuşlarının gastrointestinal sistemdeki canlılıklarını belirlemişlerdir. Düşük pH'ya karşı dayanım testinde sindirim koşullarını oluşturmak için $\mathrm{pH} 2.0$ 'de 0., 2., ve 3. saatlerde canlllik tespiti yapmışlardır. Mikroorganizmalar 3. saatin sonunda ortalama 1-2 logaritma düzeyinde düşüş göstermişlerdir. Soliman vd. (2015) L. acidophilus, L. casei ve L. plantarum suşlarının probiyotik olma özelliklerini incelemişlerdir. Bu amaçla $\mathrm{pH} 2.0$ ve $\mathrm{pH} \quad 3.0$ 'de canlilıklarını belirlemişlerdir. $L$. acidophilus $\mathrm{pH} 2.0$ 'de canll1ık gösterebilirken diğer iki mikroorganizma bu asit değerinde canlı kalamamışlardır. Dixit vd. (2013) üç farklı $L$. acidophilus suşunun probiyotik olma özelliklerini incelemişlerdir. Bu amaçla yaptıkları düşük asite direnç testinde MRS besiyerinin $\mathrm{pH}$ 'sını 2.5'e ayarlamıs ve 2 . ve 4 . saatlerdeki canlılıklarını belirlemişlerdir. Suşlar pH 2.5 'de 4 saat sonunda $\% 34, \% 52$ ve $\% 75$ oraninda canlilk göstermişlerdir.

\section{Ekzopolisakkarit Üretimi}

Ekzopolisakkarit üretimini belirlemek amaciyla yapilan analiz sonucunda 15 adet izolattan 9 tanesi sakkaroz içeren MRS katı besiyerinde parlak, mukoz bir yap1 üretmişlerdir. Şekil 1'de $L$. plantarum DA255 ve $L$. coryniformis DA263 izolatlarının sakkaroz içeren MRS katı besiyerinde oluşturdukları parlak, mukoz yap1 gösterilmektedir.

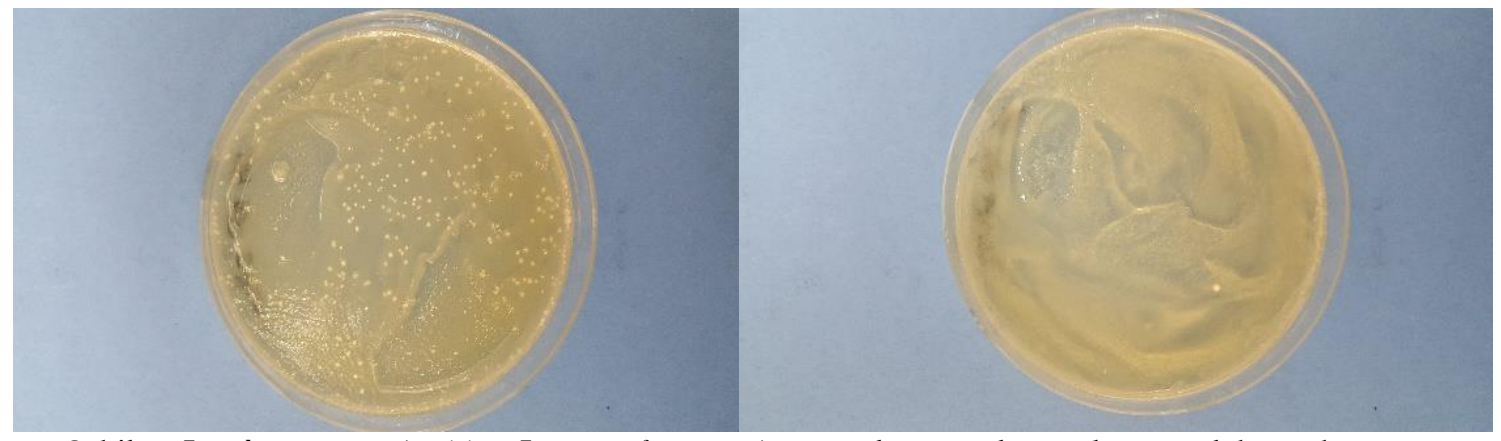

Şekil 1. L. plantarum DA255ve L. coryniformis DA263suşlarının oluşturduğu parlak, mukoz yap1 Figure 1. Glossy, mucous structure of L. plantarum DA255 and L. coryniformis DA263

İzolatların ürettiği EPS miktarı 11.9 ile $1.1 \mathrm{mg} / \mathrm{L}$ arasında belirlenmiştir. Dut bitkisinden izole edilen L. plantarum DA255 suşu $11.9 \mathrm{mg} / \mathrm{L}$ ile en yüksek EPS üreticisi olarak belirlenmiştir. Ardından turşudan izole edilen $L$. plantarum DA100 izolat1 $9 \mathrm{mg} / \mathrm{L}$ verirken en düşük miktar beyaz peynirden izole edilen L. fermentum DA134 suşunda $1.1 \mathrm{mg} / \mathrm{L}$ olarak belirlenmiştir. Aşağıda çizelgede (Çizelge 3) izolatların EPS miktarları $\mathrm{mg} / \mathrm{L}$ olarak verilmiştir.

Feng vd. (2012) çalışmasında Çin'e özel çeşitli geleneksel fermente gidalardan izole edilen laktik asit bakterilerinin ekzopolisakkarit (EPS) üretimlerini belirlemişlerdir. En yüksek EPS üretim kapasitesi $(0.859 \mathrm{~g} / \mathrm{L}) \quad$ L. plantarum (HQ259238) suşundan elde etmişlerdir. Van Geel-Schutten vd. (1998) çalışmalarında 182 adet Lactobacillus suşundan 60 tanesinin EPS ürettiğini, bunlardan 17 suşun EPS üretiminin 100 mg/L'den fazla olduğu belirlemişlerdir. Ayrıca çalışma sonunda EPS üretimi için en uygun bileşenin sakkaroz olduğunu kaydetmişlerdir. Dilna vd. (2015) çalısmasında laktik asit bakterilerinin uygun koşullar sağlandığında EPS üretimi için yararlı olacağını düşünmüşlerdir. Bu amaçla yaptıkları çalışmada L. plantarum RJF4, suşu, yapisında glukoz ve mannoz içeren bir heteropolisakkariti $3.5 \mathrm{~g} / \mathrm{L}$ düzeyinde üretmiştir. Wang vd. (2015) çalışmasında kefirden izole ettikleri L. plantarum YW32 suşunun EPS üretimini ve yapısını belirlemişlerdir. L. plantarum YW32 tarafindan üretilen EPS, yaklaşı sırasıyla 8.2:1: 4.1:4.2'lik mol oranında mannoz, fruktoz, galaktoz ve glukozdan oluşmuştur. Ayrıca oluşan EPS'nin $1.03 \times 10^{5} \mathrm{Da}^{\prime}$ lık bir molekül ağırlığına sahip olduğunu belirlemişlerdir. Üretilen EPS'nin yüksek sicaklığa $\left(283.5^{\circ} \mathrm{C}\right)$, ksidroksil ve 
süperoksit radikallerine karş1 antioksidan aktiviteye ve bazı patojen bakteriler üzerinde antibiyofilm aktivitesi ile insan HT-29 hücrelerine karşı antitümör aktivitesine sahip olduğunu belirlemişlerdir. Demir vd. (2017) yoğurttan izole ettikleri laktik asit bakterilerinin EPS üretimlerini belirlemişler ve bakterilerin EPS üretim miktarları 5.89 ile $134.60 \mathrm{mg} / \mathrm{L}$ arasında tespit etmişlerdir.

Çizelge 3. İzolatların ürettiği EPS miktarları $(\mathrm{mg} / \mathrm{L})$

Table 3. Amounts of EPS produced by isolates $(\mathrm{mg} / \mathrm{L})$ Mikroorganizma EPS miktarı $(\mathrm{mg} / \mathrm{L})$

Microorganism EPS amount $(\mathrm{mg} / \mathrm{L})$

\begin{tabular}{ll}
\hline W. cibaria DA8 & $2.95^{\mathrm{bc}}$ \\
W. cibaria DA28 & $2.40 \mathrm{bc}$ \\
L. plantarum DA100 & $9.00^{\mathrm{ab}}$ \\
L. fermentum DA134 & $1.10^{\mathrm{c}}$ \\
L. plantarum DA140 & $2.40 \mathrm{bc}$ \\
L. plantarum DA199 & $2.80 \mathrm{bc}$ \\
L. plantarum DA245 & $5.00^{\mathrm{abc}}$ \\
L. plantarum DA255 & $11.90^{\mathrm{a}}$ \\
L. coryniformis DA263 & $4.90^{\mathrm{abc}}$ \\
\hline
\end{tabular}

$\overline{a, b, c}$ Aynı sütunda farklı harflerle gösterilen değerler istatistiksel olarak farklıdır $(P<0.05)^{a, b, c}$ Different letters in same column are statistically different $(P<0.05)$.

\section{Kolesterol Asimilasyonu}

Bazı laktobasil veya bifidobakterleri içeren fermente süt ürünlerinin tüketilmesinin, insanlarda serum kolesterol düzeylerini düşürdüğü iddia edilmektedir (Burhan vd., 2017). Çalışmamızda da probiyotik olma potansiyeline sahip olduğu düşünülen 15 adet laktik asit bakterisinin kolesterol asimilasyon yetenekleri belirlenmiştir. İzolatların toplam kolesterol asimilasyon yüzdeleri $\% \quad 60.71$ ile $\% \quad 16.71$ arasında değisşmektedir. EPS üreticisi olmayan $L$. lactis DA268 \% 60.71 ile en yüksek asimilasyonu sağlamıştır. L. plantarum DA245 suşu ise iyi bir EPS üreticisi olmasina karşın kolesterol asimilasyon yüzdesi \% 16.71olarak bulunmuştur. Çizelge 4'te izolatların kolesterol asimilasyon yüzdeleri ve miktarları verilmiştir. Anandharaj ve Sivasankari (2014) çalışmalarında anne sütünden izole ettikleri Lactobasillus suşlarının farklı kolesterol miktarlarında ve safra tuzu varlığında/yokluğunda asimilasyon özelliklerini belirlemişlerdir. Suşlar safra tuzu yokluğunda $23.28-35.41 \mathrm{mg} / \mathrm{mL}$ aralığında kolesterol asimile ederken \% 0.3 safra tuzu varllğında en yüksek değer $61.05 \mathrm{mg} / \mathrm{mL}$ olarak belirlenmiştir. Burhan vd. (2017) 6 farklı L. fermentum suşunun kolesterol asimilasyon yeteneğini belirlemişlerdir. Suşlar 100 $\mathrm{mg} / \mathrm{mL}$ toplam kolesterol bulunan MRS besiyerine $10^{10} \mathrm{kob} / \mathrm{mL}$ olacak şekilde aşılanmış ve 24 saat anaerobik koşullarda inkübe edilmişlerdir. İnkübasyon sonunda suşlar \% 4.1 ve $\% \quad 8.1$ oranında asimilasyon göstermişlerdir. Castorena-Alba vd. (2017) çalışmasında farklı laktobasil ve bifidobakter suşlarının $\% 0.2$ ve $\%$ 0.4 safra tuzu varlığındaki kolesterol asimilasyon yeteneklerini belirlemişlerdir. B. lactis DSM10140 suşu $\% \quad 0.2$ safra tuzu varlığında $\%$ asimilasyon gösterirken $\% \quad 0.4$ safra tuzu varlığında bu yüzde $\% \quad 18.69$ olmuştur. Lertcanawanichakul vd. (2015) P. plantarum L14/1, P. acidilactici L25, L. plantarum L26, L. Pentosus, E. faecium N 15, suşlarinın kolesterol asimilasyon özelliklerini belirlemişlerdir. Suşlar \% 0.3 safra tuzu varllğında iyi bir düşüş göstermişlerdir. E. faecium $\mathrm{N} 15$ suşu safra tuzu varlığında \% 64.88 düşüş sağlarken safra tuzu yokluğunda bu oran \% 17.12'ye düşmüştür. Safra asitleri yüzey gerilimini azaltıci etkileri ile suda çözünmeyen lipidlerin emülsiyonlaşmasını böylece enzimlerin bağırsak lümenindeki lipitlere daha iyi etki yapmalarının yanı sıra safra içerisindeki kolesterolün çökmesini engellerler. $\mathrm{Bu}$ nedenle yapılan çoğu in vitro kolesterol asimilasyon çalısmalarında safra tuzu ortama eklenerek etkisi incelenmektedir. Bu nedenle çalışmamızda yapılan kolesterol asimilasyon denemesinde MRS besiyeri içerisine 110.70 $\mathrm{mg} / \mathrm{dL}$ kolesterolün yanı sira \% 0.3 safra tuzu eklenmiştir. 18 saat inkübasyon sonunda belli bir miktar kolesterol oluşan $\mathrm{pH}$ değişimi ile çökmüş olma ihtimali de bulunmaktadır. Ancak elde edilen asimilasyon yüzdeleri suşların bu yetenekleri hakkında öngörü sahibi olmamıza katkıda bulunmuştur. 


\begin{tabular}{|c|c|}
\hline \multicolumn{2}{|c|}{$\begin{array}{c}\text { Çizelge 4. İzolatların kolesterol asimilasyon } \\
\text { yüzdeleri }\end{array}$} \\
\hline & Total Kolesterol \\
\hline Mikroorganizma & Asimilasyonu (\%) \\
\hline Microorganism & $\begin{array}{l}\text { Total Cholesterol } \\
\text { Assimilation (\%) }\end{array}$ \\
\hline L. casei DA4 & 16.91 \\
\hline W. cibaria DA8 & 32.15 \\
\hline W. cibaria DA28 & 36.31 \\
\hline L. plantarum DA100 & 34.14 \\
\hline L. fermentum DA134 & 33.51 \\
\hline L. plantarum DA135 & 30.50 \\
\hline L. plantarum DA140 & 43.27 \\
\hline L. plantarum DA199 & 42.18 \\
\hline L. plantarum Da218 & 50.63 \\
\hline L. plantarum DA225 & 55.50 \\
\hline L. plantarum DA245 & 16.71 \\
\hline L. plantarum DA255 & 41.19 \\
\hline L. coryniformis DA256 & 50.52 \\
\hline L. corvniformis DA263 & 36.22 \\
\hline L. lactis DA268 & 60.71 \\
\hline
\end{tabular}

\section{SONUÇ}

Mikroorganizmaların, gastrointestinal sistemden rahatça geçebilmesi için safra tuzuna ve düşük pH'ya karşı dirençli olmaları gerekmektedir. Mide pH's1 1-4 arasında değişmekte ve besinlerin midede kalma süresi ortalama 3 saattir. $\mathrm{Bu}$ nedenle çalışmamızda $\mathrm{pH} 3.0$ 'de 0 ., 1 ., ve 3 . saatlerde mikroorganizmaların canlilik miktarları belirlenmiştir. 15 izolattan 7 tanesi 3. saatin sonunda canlı kalmayı başarabilmişlerdir. \% 1 safra tuzu denemesinde ise izolatların tamam 24 saat sonunda yüksek bir canlilik oran1 göstermişlerdir. Alp ve Aslım (2010) çalışmasında anne sütü ile beslenen bebeklerin dışkılarından izole ettikleri 31 Bifidobacterium spp.'nin safra tuzlarına ve düşük pH'ya karşı direnç ile ekzopolisakkarit üretimlerini belirlemiş ve EPS üretimi ile safra tuzlarına karşı direnç ve düşük pH'ya karşı direnç arasında pozitif bir korelasyon bulmuşlardır ( $\mathrm{p}<0.01)$. EPS üreticisi bazı laktobasil suşlarının safra tuzlarının da yardımı ile kolesterolü asimile edebildiği birçok in vitro çalışma ile gösterilmiştir (Horáčková vd., 2017). Tok ve Aslım (2010) çalışmalarında yüksek EPS üretimi olan suşların daha iyi bir kolesterol asimilasyonu sağladığını belirlemişlerdir. Ancak bizim çalışmamızda EPS üretimi ile kolesterol asimilasyonları arasında kuvvetli bir bağlantı bulunamamıştır. Yüksek miktarda EPS üretimi olan L. plantarum DA255 suşu \% 41.19 oranında kolesterol asimilasyonu gösterirken $L$. lactis DA268 suşu EPS üreticisi olmamasına rağmen \% 60.71'lik bir kolesterol asimilasyonu göstermiştir. $\mathrm{Bu}$ durum izolatlarin kolesterol asimilasyonunu EPS üretiminden farklı mekanizmalar ile sağladığı sonucunu düşündürmektedir. Laboratuvar ortamında yapılan deneme sonuçları ile suşların in vivo ortamda gösterebilecekleri kolesterol asimilasyon yetenekleri hakkında öngörü sahibi olunmuştur. Ancak bu suşların safra tuzu hidrolaz, HMG CoA redüktaz enzimi aktivitesi gibi baz1 özellikleri, kolesterol seviyesini düşürdüğü mekanizma (mekanizmalar) ve uygun suşları seçmek için daha fazla araştırma yapılması gerekmektedir.

\section{TEŞEKKÜR}

$\mathrm{Bu}$ çalısma Süleyman Demirel Üniversitesi, Bilimsel Araştırma Projeleri Koordinasyon Birimi (Proje No:4439-D1-15) tarafindan desteklenmiştir.

\section{KAYNAKLAR}

Ahire, J., Bhat, A., Thakare, J., M., Pawar, P., B., Zope, D., G., Jain, R., M., Chaudhari, B. L. (2012). Cholesterol assimilation and biotransformation by Lactobacillus helveticus. Biotechnol Lett, 34: 103107, doi: 10.1007/s10529-011-0733-2.

Ahn, Y., T., Kim, G., B., Lim, K., S., Baek, Y., J., Kim, H.U. (2003). Deconjugation of bile salts by Lactobacillus acidophilus isolates. Int Dairy J, 13: 303311, doi: 10.1016/S0958-6946(02)00174-7.

Alp, D. (2018). Doğal kaynaklardan izole edilen laktik asit bakterilerinin baz1 probiyotik özelliklerinin araştırılması ve in vitro bağırsak modelinde patojenlerin tutunmasinı engelleme özelliklerinin belirlenmesi. Süleyman Demirel Üniversitesi Fen Bilimleri Enstitüsü G1da Mühendisliği Anabilim Dalı Doktora Tezi, Isparta, Türkiye, $124 \mathrm{~s}$.

Alp, D., Ertürkmen, P. (2017). Probiyotik olarak kullanılan Lactobacillus spp. suşlarının kolesterol düşürücü etkileri ve olasi mekanizmalar. Makü Febed, 8(1): 108-113. 
Alp, G., Aslim, B. (2010). Relationship between the resistance to bile salts and low ph with exopolysaccharide (eps) production of Bifidobacterium spp. isolated from infants feces and breast milk. Anaerobe, 16: 101-105.

Anandharaj, M., Sivasankari, B. (2014). Isolation of potential probiotic Lactobacillus oris HMI68 from mother's milk with cholesterol-reducing property. J Biosci Bioeng, 118 (2): 153-159, doi: 10.1016/j.jbiosc.2014.01.015.

Anila, K., Kunzes, A., Bhalla, T.C. (2016). In vitro cholesterol assimilation and functional enzymatic activities of putative probiotic Lactobacillus ssp. isolated from fermented foods/beverages of North West India. J Nutr Food Sci, 6 (2), doi:10.4172/2155-9600.1000467.

Arief, I.I., Jenie, B.S., Astawan, M., Kazuhito, F., Witarto, A.B. (2015). Identification and probiotic characteristics of lactic acid bacteria isolated from Indonesian local beef. Asian-Australas J Anim Sci, 9(1): 25-36, doi:10.3923/ajas.2015.25.36.

Belviso, S., Giordano, M., Zeppa, P.D.G. (2009). In vitro cholesterol-lowering activity of Lactobacillus plantarum and Lactobacillus paracasei strains isolated from the Italian Castelmagno PDO Cheese. Dairy Sci Technol, 89: 169-176, doi: 10.1051/dst/ 2009004.

Burhan, H.S.A., Priyambada, E., Arief, I.I. (2017). Potential of lactic acid bacteria isolated from Dangke and Indonesian Beef as Hypocholesterolaemic Agent. J Anim Sci Technol, 40 (2):136-142, doi: 10.5398/medpet. 2017.40.2.136.

Castorena Alba, M.M., Vázquez Rodríguez, J.A., López Cabanillas Lomelí, M., González Martínez, B.E. (2017). Cholesterol assimilation, acid and bile survival of probiotic bacteria isolated from food and reference strains. CyTA, 1(16):36-41, doi: 10.1080/19476337.2017.1335347.

Chang Qing, Y., Li Rong, L. (2015). Cloning and expression of bile salt hydrolase gene from Lactobacillus plantarum M1-Uvs29, (Eng. ed.) Volume 2, J Northeast Agric Univ, 60-66.

Coşkun, T. (2006). Pro-pre ve sinbiyotikler. CSHD, 49: 128-148.
Demir, E., Kaygusuz, E., Kılıç, G., Yüce, S., Soyuçok, A. (2017). Yoğurt örneklerinden izole edilmiş laktik asit bakterilerinin moleküler yöntemlerle tanımlanması ve ekzopolisakkarit üretimlerinin belirlenmesi. Makü Febed, 8(1): 262267.

Dilna, S.V., Surya, H., Aswathy, R.G., Varsha, K.K., Sakthikumar, D.N., Pandey, A., Nampoothiri, K.M. (2015). Characterization of an exopolysaccharide with potential health benefit properties from a probiotic Lactobacillus plantarum RJF4. Food Sci Technol Int, 64: 1179-1186, doi:10.1016/j.lwt.2015.07.040.

Dixit, G., Samarth, D., Bhadekar, R. (2013). Comparative studies on potential probiotic characteristics of Lactobacillus acidophilus strains. Eurasia J Biosci, 7: 1-9, doi: 10.5053/ejobios. 2013.7.0.1.

Eryllmaz, F. (2011). Vajinal Sekresyondan izole edilen laktik asit bakterilerine ait bazı suşların potansiyel probiyotik özelliklerin belirlenmesi. Ankara Üniversitesi Biyoteknoloji Enstitüsü, Doktora Tezi, Ankara, Türkiye, $95 \mathrm{~s}$.

Feng, M., Chen, X., Li, C., Nurgul, R., Dong, M. (2012). Isolation and identification of an exopolysaccharide-producing lactic acid bacterium strain from chinese paocai and biosorption of $\mathrm{Pb}(\mathrm{II})$ by its exopolysaccharide. $J$ Food Sci, 77:(6)11-117, doi: 10.1111/j.17503841.2012.02734.x.

Gill, H.S., Guarner, F. (2004). Probiotics and human health: a clinical perspective. Postgrad Med J, 80:516-526, doi: 10.1136/pgmj.2003.008664.

Gilliland, S.E., Nelson, C.R., Maxwell, C. (1985): Assimilation of cholesterol by Lactobacillus acidophilus. Appl Environ Microbiol, 49: 377.

Hofmann, A.F., Molino, G., Milanese, M., Belforte, G. (1983). Description and simulation of a physiological pharmacokinetic model for the metabolism and enterohepatic circulation of bile acids in man compartmental model of cholic acid in man. Eur J Clin Investig 71: 1003-1022.

Horáčková, S., Plocková, M., Demnerová, K. (2017). Importance of microbial defence systems to bile salts and mechanisms of serum cholesterol 
reduction. Biotechnol, 36:(3)682-690, doi:10.1016/J.Biotechadv.2017.12.005.

Horáčková, S., Žaludová, K., Plocková, M. (2011). Stability of selected Lactobacilli in the conditions simulating those in the gastrointestinal tract czech. Czech J Food Sci, 29: 30-35.

Iranmanesh, M., Ezzatpanah, H., Mojgani, N. (2014). Antibacterial activity and cholesterol assimilation of lactic acid bacteria isolated from traditional Iranian dairy products. Food Sci Technol Int, 58: 355-359, doi: 10.1016/j.lwt.2013.10.005.

Jamaly, N., Benjouad, A., Bouksaim, M. (2011). Probiotic potential of Lactobacillus strains isolated from known popular traditional moroccan dairy products. Br Microbiol Res J, 1(4): 79-94.

Kaur, I., P., Chopra, K., Saini, A. (2002). Probiotics: potential pharmaceutical applications. Eur J Pharm Sci, 15: 1-9, doi: 10.1016/S09280987(01)00209-3.

Kopp Hoolihan, L. (2001). Prophylactic and therapeutic uses of probiotics: a review. J Am Diet Assoc,101: 229-241, doi: 10.1016/S00028223(01)00060-8.

Lertcanawanichakul, M., Kannai, J., Wongmuang, P., Tharaporn, S. (2015). Cholesterol-lowering potentials of lactic acid bacteria with potential probiotic properties. Int J Pharmtech Res, 7(3): 463470.

Moal, V.L., Servin, A.L. (2014). Anti-infective activities of Lactobacillus strains in the human intestinal microbiota: from probiotics to gastrointestinal anti-infectious biotherapeutic agents. Clin Microbiol Rev, 27(2): 167-199, doi: 10.1128/CMR.00080-13.

Noh, D.O,. Kim, S.H., Gilliland, S.E. (1997). Incorporation of cholesterol into the cellular membrane of Lactobacillus acidopbilus ATCC 43121. J Dairy Sci. 80:(12) 3107-3113.

Öztürk, Z., Tiryaki Gündüz, G. (2017). Gıda kaynaklı patojenlerin inhibisyonunda probiyotik mikroorganizmaların kullanımı. GID $A, 43$ (4): 533-548, doi: 10.15237/gida.GD17112.

Pinto, M.G.V., Franz, C.M.A.P., Schillinger, U., Holzapfel, W.H. (2006). Lactobacillus spp. with in vitro probiotic properties from human faeces and traditional fermented products. Int $J$ Food Microbiol, 109:205-214, doi: 10.1016/ j.ijfoodmicro.2006.01.029.

Sahadeva, R.P.K., Leong, S.F., Chua, K.H., Tan, C.H., Chan, H.Y., Tong, E.V., Wong, S.Y.W., Chan, H.K. (2011). Survival of commercial probiotic strains to ph and bile. Int Food Res J, 18(4):1515-1522.

Sharma, K., Sharma, N., Sharma, R. (2016). Identification and evaluation of in vitro probiotic attributes of novel and potential strains of lactic acid bacteria isolated from traditional dairy products of North-West Himalayas. J Clin Microbiol Biochem Technol 2(1): 018-025, doi: 10.17352/jcmbt.000011.

Smitinont, T., Tansakul, C., Tanasupawat, T., Keeratipibul, S., Navarini, L., Bosco, M., Cescutti, P. (1999). Exopolysaccharide-producing lactic acid bacteria strains from traditional thai fermented foods: isolation, identification and exopolysaccharide characterization. Int J Food Microbiol, 51:105-111, doi: 10.1016/S01681605(99)00094-X.

Soliman A.H.S., Sharoba, A.M., Bahlol, H.E.M., Soliman, A.S., Radi, O.M.M. (2015). Evaluation of Lactobacillus acidophilus. Lactobacillus casei and Lactobacillus plantarum for probiotic characteristics. JMEAST, 5:(1) 10-18.

Syah, S.P., Sumantri, C., Arief, I.I., Taufik, E. (2017). Isolation and identification of indigenous lactic acid bacteria by sequencing the $16 \mathrm{~S}$ rRNA from Dangke, a traditional cheese from Enrekang, South Sulawesi. Pak. J. Nutr, 16(5):384392. doi: $10.3923 / \mathrm{pjn} .2017 .384 .392$.

Tok, E. (2007). Probiyotik olarak kullanilabilecek bazı laktik asit bakterilerinin kolesterol giderimi özellikleri ve safra tuzu dekonjugasyonu etkilerinin araştırılması. Gazi Üniversitesi Fen Bilimleri Enstitüsü, Biyoloji Anabilim Dalı, Yüksek Lisans Tezi, Ankara, Türkiye, 95s.

Tok, E., Aslim, B. (2010). Cholesterol removal by some lactic acid bacteria that can be used as probiotic. Microbiol Immunol, 54: 257-264, doi: 10.1111/j.1348-0421.2010.00219.x. 
Tokatlı, M., Gülgör. G.. Elmacı, S. Arslanköz. N., Özçelik, F. (2015). In vitro properties of potential probiotic indigenous lactic acid bacteria originating from traditional pickles BioMed Res Int,. ID 315819. s 8, doi: 10.1155/2015/315819.

Özden Tuncer, B., Tuncer, Y. (2014). Exopolysaccharide producer Streptococcus thermophilus St8.01 strain; a potential probiotic culture. GIDA 39 (4):195-202.

Ulukaya, E. (çeviri ed.) 1997. Biyokimya. Biochemistry. 2. baskıdan çeviri, Nobel Tip Kitabevi, İstanbul, Türkiye. 205.

Uraipan, S., Hongpattarakere, T. (2015). Antagonistic characteristics against food-borne pathogenic bacteria of lactic acid bacteria and bifidobacteria isolated from feces of healthy thai infants. Jundishapur J Microbiol, 8(6):18264, doi: 10.5812/jjm.8(6)2015.18264.

Ünal, E., Erginkaya, Z. (2010). Probiyotik mikroorganizmaların mikroenkapsülasyonu. GIDA. 35 (4): 297-304.

Van Geel-Schutten, G.H., Flesch, F., Brink, B., Smith, M.R., Dijkhuizen, L. (1998). screening and characterization of Lactobacillus strains producing large amounts of exopolysaccharides. Appl Microbiol Biotechnol, 50: 697-703.
Vinderola, C.G., Prosello, W., Ghiberto, D., Reinheimer, J.A. (2000). Viability of probiotic Bifidobacterium, Lactobacillus acidopbilus and Lactobacillus casei and nonprobiotic microflora in Argentinian Fresco Cheese. J Dairy Sci, 83: 19051911, doi: 10.3168/jds.S0022-0302(00)75065-X.

Wang, S.C., Chang, C.K., Chan, S.C., Shieh, J.S., Chiu, C.K., Duh, P. (2014). Effects of lactic acid bacteria isolated from fermented mustard on lowering cholesterol. Asian Pac J Trop Biomed, 4(7): 523-528, doi: 10.12980/APJTB.4.201414B54.

Wang, J., Zhao, X., Tian, Z., Yang, Y., Yang, Z. (2015). Characterization of an exopolysaccharide produced by Lactobacillus plantarum YW11 isolated from Tibet Kefir. Carbohydr Polym, 125: 16-25, doi: 10.1016/j.ijbiomac.2014.12.006.

Xiao, K. (2014). Bile resistance in Lactobacillus rhamnosus GG: Stability and mechanisms. Master Dissertation, Helsinki University, Finland, 72p.

Xie, N., Cui, Y., Yin, Y.N., Zhao, X., Yang, W., Wang, Z., Fu, F., Tang, Y., Wang, X., Liu, X., Wang, C., Lu, F. (2011). Effects of two Lactobacillus strains on lipid metabolism and intestinal microflora in rats fed a high-cholesterol diet. BMC Complement Altern Med, 11:53. 